\title{
THE EFFECTS OF SELF ESTEEM, SOCIAL SUPPORT, AND RELIGIOUS ORIENTATION TOWARD CYBERBULLYING INTENTION ON ADOLESCENTS AT SENIOR HIGH SCHOOL
}

\author{
Diah Roro Kinanti \\ kinanfadhila@gmail.com \\ mailto:afifah.fauziyyah.af@gmail.com \\ Anggota HIMPSI Provinsi Jawa Barat
}

\author{
Netty Hartati \\ netty.hartati@uinjkt.ac.id \\ Fakultas Psikologi UIN Syarif Hidayatullah \\ Jakarta
}

\begin{abstract}
Cyberbullying intention has penetrated into adolescence and even in the school environment. Moreover, coupled with the widespread use of smartphones among adolescents. Number of Internet users in 2014 in Banten province and 3.3 million users in the age of 10-24 years of as much as $75.5 \%$. Subjects of this study are 210 high school students in the area of Triguna Utama School. This study showed various results of cyberbullying intention variance proportion that affected by self-esteem, emotional support, instrumental support, informational support, companionship support, intrinsic orientation and ekstrinsic orientation which is 17,9\% with the significant contribution variable as follows: companionship support, intrinsic orientation, and ekstrinsic orientation.
\end{abstract}

Keyword: cyberbullying intention, self-esteem, social support, religious orientation

\begin{abstract}
Abstrak
Intensi cyberbullying telah merambah ke remaja bahkan di dalam lingkungan sekolah. Apalagi ditambah dengan maraknya penggunaan smartphone di kalangan remaja. Jumlah pengguna internet tahun 2014 di provinsi Banten sebanyak 3,3 juta dan pengguna di usia 10 - 24 tahun sebanyak $75,5 \%$. Subyek dalam penelitian ini berjumlah 210 pelajar SMA di sekolah Triguna Utama. Hasil penelitian menunjukkan bahwa bervariasinya proporsi varians intensi cyberbullying yang disebabkan oleh self-esteem, dukungan emosional, dukungan instrumental, dukungan informational, dukungan jaringan sosial, orientasi intrinsik dan orientasi ekstrinsik sebesar $17,9 \%$ dengan kontribusi variabel yang signifikan adalah dukungan jaringan sosial, orientasi intrinsik dan orientasi ekstrinsik.
\end{abstract}

Kata kunci: cyberbullying intention, self-esteem, social support, religious orientation 


\section{PENDAHULUAN}

Perkembangan internet yang semakin canggih membuat banyak situs, aplikasi dan media sosial mudah untuk diakses dan digunakan sebagai sarana komunikasi satu sama lain tanpa adanya batas ruang dan waktu. Kementerian Komunikasi dan Informatika (Kemkominfo) pada web resmi nya menyatakan bahwa pengguna internet di Indonesia hingga saat ini telah mencapai 82 juta orang dan dari jumlah pengguna internet tersebut, $80 \%$ di antaranya adalah remaja berusia 15-19 tahun. Menurut Rousseau (dalam Sarwono, 2010) menyatakan bahwa perkembangan individu pada usia 15-20 tahun dinamakan masa kesempurnaan remaja (adolescence proper) dan merupakan puncak perkembangan emosi. Dalam tahap ini terjadi perubahan dari individu yang cenderung mementingkan diri sendiri menjadi cenderung memperhatikan orang lain dan cenderung memperhatikan harga diri. Sehingga dapat disimpulkan bahwa hampir sebagian besar kasus cyberbullying terjadi pada individu usia remaja.

Hasil penelitian Vandebo sch \& Van Cleemput (dalam Corcoran, 2015) yang mengambil sampel siswa berusia 10 sampai 18 tahun mengatakan bahwa cyberbullying ditandai oleh adanya kecenderungan untuk menyakiti dan dipersepsikan dengan perilaku yang menyakitkan oleh korban, perilaku negatif yang dilakukan berulang. Ajzen (2005) menyatakan bahwa intensi adalah sebuah indikasi dari kesiapan seseorang untuk menunjukkan perilaku, dengan kata lain intensi merupakan dorongan dalam diri atau niat sebelum terjadinya perilaku. Intensi dapat meramalkan secara akurat berbagai kecenderungan perilaku. Berdasarkan theory of planned behavior, intensi dapat dibagi menjadi 3 faktor, pertama adalah faktor personal dari individu tersebut, kedua bagaimana pengaruh sosial, dan ketiga berkaitan dengan kontrol yang dimiliki individu (Ajzen, 2005).

Willard (2007) mendefinisikan cyberbullying sebagai perbuatan kejam terhadap orang lain dengan mengirimkan atau mem-posting material yang menyakitkan bagi korbannya atau yang berkaitan dengan agresi sosial dengan menggunakan internet atau teknologi digital lainnya. Menurut Willard (2007) terdapat delapan bentuk cyberbullying, yaitu flaming (pertengkaran secara online dengan menggunakan pesan elektronik yang berisikan kata-kata kasar dan vulgar); harassment (berulang kali mengirimkan pesan mesum, kasar, dan menghina); denigration (mengirim atau mem-posting gosip atau rumor mengenai seseorang guna merusak reputasi atau pertemanan orang tersebut); impersonation (berpura-pura menjadi orang lain dan mengirim atau mem- posting materi agar orang tersebut mendapatkan masalah atau bahaya atau untuk merusak reputasi dan pertemanan orang tersebut); outing (menyebarkan rahasia atau informasi memalukan dari seseorang secara online); trickery (membujuk seseorang untuk menceritakan rahasia atau informasi memalukan yang dia miliki lalu menyebarkan rahasia atau informasi tersebut secara online); exclusion (dengan sengaja mengeluarkan seseorang dari grup online secara kasar); cyberstalking (berulang kali mengirimkan konten pelecehan dan fitnah secara intens kepada seseorang yang menyebabkan orang tersebut merasa terancam dan menciptakan rasa takut yang signifikan). 
Selain self esteem dan dukungan sosial, orientasi religius yang dimiliki individu juga merupakan faktor lain yang mempengaruhi perilaku cyberbullying. Individu yang memiliki konsep orientasi religius akan mempengaruhi tingkah lakunya dan menjalankan apa yang dianggapnya sebagai perintah agama serta menghindari tindakan-tindakan negatif. Tindakan negatif yang dimaksud salah satunya adalah cyberbullying. Seseorang dengan religiusitas intrinsik adalah orang yang menginternalisasi keyakinan agamanya secara total, bukan sekedar kehadiran di tempat ibadah belaka. Dalam dimensi ekstrinsik ini yaitu ketika individu menggunakan agama untuk tujuan pribadi, seperti status sosial, kepentingan pembenaran diri, dan sering selektif dalam membentuk keyakinan agar sesuai dengan tujuan sendiri.

\section{KAJIAN TEORI}

Itensi

Chaplin (2005) mendefinisikan intensi sebagai suatu perilaku yang disadari, sengaja dan atas kemauan sendiri. Ajzen (2005) menyatakan bahwa intensi adalah sebuah indikasi dari kesiapan seseorang untuk menunjukkan perilaku, dengan kata lain intensi merupakan dorongan dalam diri atau niat sebelum terjadinya perilaku.

\section{Cyberbullying}

Definisi cyberbullying yang digunakan pada penelitian ini yaitu perbuatan kejam terhadap orang lain dengan mengirimkan atau mem-posting material yang menyakitkan bagi korbannya atau yang berkaitan dengan agresi sosial dengan menggunakan internet atau teknologi digital lainnya (Willard, 2007).

\section{Self-Esteem}

Definisi self-esteem yang akan dipakai dalam penelitian ini yaitu mengatakan bahwa self-esteem adalah evaluasi terhadap diri sendiri baik positif maupun negatif (Rosenberg dalam Hinduja \& Patchin, 2010).

\section{Dukungan Sosial}

Definisi yang dipakai dalam penelitian ini menggunakan teori dari Sarafino (2011) yang mengatakan bahwa social support adalah kenyamanan, perhatian, penghargaan atau bantuan yang diperoleh individu dari orang lain, dimana orang lain disini dapat diartikan sebagai individu perorangan atau kelompok.

\section{Orientasi Religius}

Pada penelitian ini definisi orientasi religius yang digunakan adalah menurut teori Allport dan Ross (1967) yaitu sebagai sistem cara pandang individu mengenai kedudukan agama dalam hidupnya, yang menentukan pola bentuk relasi individu dengan agamanya. 


\section{METODE PENELITIAN}

\section{Populasi, sampel dan teknik pengambilan sampel}

Populasi dalam penelitian ini merupakan pengguna aktif internet pada remaja sekolah menengah atas dengan kisaran usia antara 15- 18 tahun. Sampel dalam penelitian ini adalah remaja sekolah menengah atas yang menggunakan internet yang berjumlah 210 orang dengan kriteria sebagai berikut :

1. Responden berusia 15-18 tahun merupakan remaja sekolah menengah atas Triguna Utama di Tangerang Selatan.

2. Responden aktif mengakses internet atau soial media seperti Facebook, Twitter, Instagram, Path, YouTube, Ask.fm, Line, Whatsapp, BBM, dan lainlain dalam kurun waktu minimal 6 bulan terakhir.

3. Bersedia menjadi responden.

Teknik pengambilan sampel yang digunakan dalam penelitian ini bersifat nonprobability sampling, yaitu besarnya peluang untuk terpilihnya anggota populasi sebagai sampel tidak sama. Teknik sampling yang digunakan adalah purposive sampling yaitu pengambilan sampel secara sengaja sesuai dengan persyaratan sampel yang sudah ditentukan.

\section{Instrumen penelitian}

Terdapat empat alat ukur yanng digunakan peneliti dalam penelitian ini :

1. Instrumen Intensi Cyberbullying

Peneliti menggunakan skala cyberbullying dari Willard (2007) yang peneliti sudah modifikasi, sebanyak 20 item dengan menggunakan skala Likert untuk mengukur intensi cyberbullying dari perilaku dan aktivitas cyberbullying.

\section{Instrumen Self-Esteem}

Self Esteem diukur menggunakan alat ukur yang telah di modifikasi dari Rosenberg Self-Esteem Scale dengan 10 item di dalamnya.

\section{Instrumen Social Support}

Social Support diukur dengan menggunakan skala yang merujuk berdasarkan teori Sarafino (2011). Alat ukur ini terdiri dari 20 item yang terdiri dari empat dimensi yaitu dukungan emosional, dukungan instrumental, dukungan informasi, dan dukungan jaringan sosial.

\section{Instrumen Orientasi Religius}

Orientasi Religius diukur dengan menggunakan alat ukur Intrinsic / Ekstrinsic R Scale (I/E R Scale). Alat ukur ini terdiri dari 14 item yang terdiri dari dua dimensi yaitu orientasi instrinsik dan orientasi ekstrinsik.

\section{HASIL PENELITIAN}

\section{Besaran Muatan Independent Variable terhadap Dependent Variable}

Berdasarkan hasil penelitian yang dilakukan terhadap 210 responden, responden perempuan lebih banyak dibandingkan dengan responden laki-laki. Aplikasi yang 
sering digunakan pada saat online adalah membuka sosial media sebanyak $66 \%$. Dapat dilihat pada tabel intensi cyberbullying, bahwa sebanyak $60 \%$ responden menjawab pernah melakukan cyberbullying dan sebanyak $40 \%$ responden menyatakan tidak pernah melakukan cyberbullying.

Tabel 1

Gambaran Subyek Penelitian

\begin{tabular}{lll}
\hline Jenis Kelamin & Laki-laki & $42 \%$ \\
& Perempuan & $58 \%$ \\
Intensi Cyberbullying & Pernah & $40 \%$ \\
& Tidak Pernah & $60 \%$ \\
Aplikasi yang sering digunakan & Sosial Media & $66 \%$ \\
& Game Online & $12 \%$ \\
& Grup Online & $18 \%$ \\
& Lain-lain & $4 \%$ \\
\hline
\end{tabular}

Berdasarkan data pada tabel 1 dapat dilihat bahwa perolehan $R$-square sebesar 0,179 atau $17,9 \%$. Hal tersebut artinya adalah proporsi varians dari intensi cyberbullying yang dijelaskan oleh self-esteem, dukungan emosional, dukungan instrumental, dukungan informational, dukungan jaringan sosial, orientasi intrinsik dan orientasi ekstrinsik sebesar 17,9\% sedangkan sisanya sebesar $82,1 \%$ dipengaruhi oleh variabel lain di luar penelitian ini.

Tabel 2

Anova keseluruhan IV terhadap DV

\begin{tabular}{llrrrrr}
\hline Model & & Sum of Squares & df & $\begin{array}{c}\text { Mean } \\
\text { Square }\end{array}$ & F & Sig. \\
\hline \multirow{1}{*}{$\mathbf{1}$} & Regression & 3220.966 & 7 & 460.138 & 6.275 & $.000^{\mathrm{b}}$ \\
& Residual & 14812.826 & 202 & 73.331 & & \\
& Total & 18033.792 & 209 & & & \\
\hline
\end{tabular}

Berdasarkan tabel 2 di atas diketahui bahwa nilai $\mathrm{p}$ (sig) pada kolom paling kanan adalah sebesar 0,000 atau dengan nilai $p<0,05$. Hal tersebut artinya adalah terdapat pengaruh yang signifikan dari self-esteem, dukungan emosional, dukungan instrumental, dukungan informational, dukungan jaringan sosial, orientasi intrinsik dan orientasi ekstrinsik terhadap intensi cyberbullying. 


\section{Tabel 3}

Koefisien Regresi

\begin{tabular}{llrrrrr}
\hline \multirow{2}{*}{ Model } & & UC & SC & t & Sig.1. \\
& & B & S.E & Beta & & \\
\hline \multirow{4}{*}{1} & (Constant) & 45.277 & 7.982 & & 5.672 & .000 \\
& Self Esteem & -.017 & .063 & -.018 & -.264 & .792 \\
& Dukungan Emosional & -.072 & .092 & -.058 & -.781 & .436 \\
& Dukungan Instrumental & -.041 & .094 & -.034 & -.437 & .662 \\
& Dukungan Informational & -.072 & .081 & -.078 & -.889 & .375 \\
& Dukungan Jaringan Sosial & .271 & .095 & .238 & 2.859 & .006 \\
& Orientasi Intrinsik & -.215 & .074 & -.213 & -2.896 & .004 \\
& Orientasi Ekstrinsik & .241 & .076 & .231 & 3.170 & .002 \\
\hline
\end{tabular}

Intensi Cyberbullying $=45,277-0,017$ self esteem - 0,072 dukungan emosional 0,041 dukungan instrumental - 0,072 dukungan informasional $+0,271$ dukungan jaringan sosial * $-0,215$ orientasi intrinsik* $+0,241$ orientasi ekstrinsik*. Dari persamaan regresi tersebut dapat dilihat bahwa dari tujuh hipotesis minor, hanya terdapat tiga yang signifikan, yaitu koefisien regresi dukungan jaringan sosial, orientasi intrinsik dan orientasi ekstrinsik. (*) Signifikan

\section{Proporsi varian}

1. Variabel dukungan emosional memberikan sumbangan sebesar $1,7 \%$ terhadap varians intensi cyberbullying. Sumbangan tersebut tidak signifikan dengan $\mathrm{F}$ change $=3,518, \mathrm{df} 1=1, \mathrm{df2}=207$ dan Sig. $\mathrm{F}$ change $=0,062(\mathrm{p}>0,05)$.

2. Variabel dukungan instrumental memberikan sumbangan sebesar $0 \%$ terhadap varians intensi cyberbullying. Sumbangan tersebut tidak signifikan dengan $\mathrm{F}$ change $=0,002, \mathrm{df} 1=1, \mathrm{df} 2=206$ dan Sig. $\mathrm{F}$ change $=0,967(\mathrm{p}>0,05)$.

3. Variabel dukungan informational memberikan sumbangan sebesar $0 \%$ terhadap varians intensi cyberbullying. Sumbangan tersebut tidak signifikan dengan $F$ change $=0,002, \mathrm{df} 1=1, \mathrm{df} 2=205$ dan Sig. $F$ change $=0,961(\mathrm{p}>$ $0,05)$.

4. Variabel dukungan jaringan sosial memberikan sumbangan sebesar $3.6 \%$ terhadap varians intensi cyberbullying. Sumbangan tersebut signifikan dengan F change $=7,671, \mathrm{df} 1=1, \mathrm{df} 2=204$ dan Sig. $\mathrm{F}$ change $=0,006(\mathrm{p}<0,05)$.

5. Variabel orientasi intrinsik memberikan sumbangan sebesar $8.3 \%$ terhadap varians intensi cyberbullying. Sumbangan tersebut signifikan dengan $\mathrm{F}$ change $=19,540, \mathrm{df} 1=1, \mathrm{df} 2=203$ dan Sig. F change $=0,004(\mathrm{p}<0,05)$.

6. Variabel orientasi ekstrinsik memberikan sumbangan sebesar $4.1 \%$ terhadap varians intensi cyberbullying. Sumbangan tersebut signifikan dengan $\mathrm{F}$ change $=10,049, \mathrm{df} 1=1, \mathrm{df} 2=202$ dan Sig. F change $=0,002(\mathrm{p}<0,05)$. 


\section{KESIMPULAN DAN SARAN}

\section{Kesimpulan}

Berdasarkan hasil analisis uji multiple regression, maka dapat disimpulkan bahwa terdapat pengaruh yang signifikan dari self- esteem, social support (dukungan emosional, dukungan instrumental, dukungan informational, dukungan jaringan sosial) dan orientasi religius (orientasi intrinsik, orientasi ekstrinsik) terhadap intensi cyberbullying. Dari hasil analisis regresi, didapatkan bahwa intensi cyberbullying dipengaruhi oleh self-esteem, social support (dukungan emosional, dukungan instrumental, dukungan informational, dukungan jaringan sosial) dan orientasi religius (orientasi intrinsik, orientasi ekstrinsik) secara bersama-sama sebesar $17,9 \%$.

\section{Diskusi}

Berdasarkan hasil penelitian dan pengujian hipotesis yang telah dilakukan menunjukkan bahwa dukungan jaringan sosial, orientasi intrinsik dan orientasi ekstrinsik memiliki pengaruh yang signifikan terhadap intensi cyberbullying. Studi sebelumnya menemukan bahwa intensi cyberbullying adalah prediktor terkuat (dibandingkan norma subjektif dan kontrol perilaku yang dirasakan) terhadap kecenderungan remaja untuk melakukan cyberbullying (Jacobs, 2015). Dimensidimensi yang berpengaruh secara signifikan terhadap intensi cyberbullying diantaranya adalah dukungan jaringan sosial, orientasi intrinsik, dan orientasi ekstrinsik. Hasil penelitian ini sejalan dengan penelitian yang dilakukan Offen (2012) yang menyatakan bahwa pelaku bullying sering menerima dukungan dari teman sebaya lebih kuat dari korban terutama jika mereka afiliasi dengan lainnya pengganggu dan membentuk kelompok yang mendukung intensi bullying. Pada variabel orientasi intrinsik penelitian ini juga sejalan dengan penelitian sebelumnya yang menyatakan bahwa individu yang memiliki orientasi intrinsik cenderung memiliki sikap agresi yang rendah karena ajaran agama tertanam dalam diri individu tersebut sehingga termotivasi dan menimbulkan perilaku secara konsisten. Sedangkan pada variabel ekstrinsik cenderung memiliki sikap agresi yang lebih tinggi (Leach, Berman \& Eubanks , 2008).

Adanya program mentoring siswa junior di sekolah merupakan salah satu cara mengantisipasi perilaku bullying. Secara umum, hasil penelitian ini juga menunjukkan bahwa orientasi religius memiliki pengaruh yang signifikan terhadap intensi cyberbullying. Hal ini sejalan dengan penelitian Leach, Berman \& Eubanks (2008). Dalam penelitian yang dilakukan oleh Leach, Berman \& Eubanks (2008), hasilnya menyebutkan bahwa individu yang memiliki orientasi religius intrinsik di dirinya cenderung rendah dalam perilaku agresif dibandingkan dengan individu yang memiliki orientasi ekstrinsik.

\section{Saran}

\section{Saran Teoritis}

1. Bagi peneliti lain yang tertarik untuk meneliti intensi cyberbullying agar melibatkan independent variable seperti jenis kelamin atau budaya sehingga memiliki hasil yang lebih kompleks dan komperehensif. Dengan mempertimbangkan variabel-variabel tersebut, diharapkan penelitian 
selanjutnya akan lebih beragam dan menyempurnakan hasil penelitian sebelumnya.

2. Pemilihan sampel dapat lebih tepat sasaran seperti langsung memilah partisipan menjadi pelaku, korban atau bystander cyberbullying. Sehingga didapatkan data yang lebih spesifik dan terarah.

\section{Saran Praktis}

1 Pada penelitian ini ditemukan bahwa dimensi dukungan jaringan sosial dan orientasi ekstrinsik berpengaruh terhadap intensi cyberbullying secara positif. Bagi para pengguna internet diharapkan dapat memilih teman yang dapat mengarahkan ke hal yang baik selama beraktivitas secara online untuk menghindari intensi cyberbullying.

2. Remaja hendaknya lebih menanamkan nilai-nilai agama di dalam dirinya serta dijadikan pedoman dalam berperilaku sehingga dapat mengurangi intensi cyberbullying.

\section{DAFTAR PUSTAKA}

Ajzen, I. (2005). Attitudes, personality, and behavior, 2nd Ed. England: Open University Press.

Ang, R.P., \& Goh, D.H. (2010). Cyberbullying among adolescents: the role of affective and cognitive empathy, and gender. Child Psychiatry and Human Development. 41, 387-397. doi: 10.1007/s10578-010-01763Arriaga, S., Garcia, R., Amaral, I \& Daniel,

F. (2017). Bullying, cyberbullying and social support: a study in a portuguese school. Proceedings of INTED2017 Conference

Barlett, C.P., Prot, S., Anderson \& Gentile,D. (2016). An empirical examination of the strength differential hypothesis in cyberbullying behavior. Psychologyof Violence. 10.1037/vio0000032

Baumeister, R. F., dkk. (2003). Does high self-esteem cause better performance, interpersonal success, happiness, or healthier lifestyles?. Psychological Science in the Public Interest, 4, 1-44.

Benhorin, S \& McMahon, S. (2008). Exposure to violence and aggression: protective roles of social support among urban african american youth. Journal Of Community Psychology, Vol. 36, No. 6, 723-743

Chaplin, J P. (2005). Kamus lengkap psikologi. Jakarta : Rajawali Pres

Cochrane, Krista R. (2008). Exploring cyberbullying in saskatchewan.

Department of Education Psychology and Special Education University of Saskatchewan Saskatoon

Davidson, L.M \& Michelle K.D. (2007). Social support as a moderator between victimization and internalizing externalizing distress from bullying. School Psychology Review. No. 3, pp. 383-405

Donegan, Richard. (2012). Bullying and cyberbullying: history, statistics, law, prevention and analysis. the elon journal of undergraduate research in communications. Strategic Communication Elon University Earnshaw,

E. L. A. (2000). Religious orientation and meaning in life: an exploratory study. National Undergraduate Research Clearinghouse 
Eskisu, Mustafa. (2014). The relationship between bullying, family functions and perceived social support among high school students. Social and Behavioral Sciences 159; $492-496$

Fishbein, M., \& Ajzen, I. (1975). Belief, attitude, intention, and behavior: an introduction to theory and research. Reading, MA: Addison-Wesley.

Galanou, C., Galanakis, M., Alexopoulos, E \& Darviri, C. (2014). Rosenberg self- esteem scale greek validation on student sample. Journal of Psychology. 5, 819-827

Ghufron, M. Nur \& Risnawati, S. R. (2010). Teori-teori psikologi. Yogyakarta: Ar-Ruzz Media

Gustainiene, L \& Valiune, D. (2015). Comparison of attitudes towards help seeking between schoolchildren with and without experience of cyberbullying. Social and Behavioral Sciences. 205 (2015) $391-395$

Healy, Fiona. (2013). Cyber bullying and its relationship with self esteem and quality of friendships amongst adolescent females in ireland. Dublin Business School

Heirman, W \& Walrave, M. (2012). Predicting adolescent perpetration in cyberbullying: an application of the theory of planned behavior. Psicothema

Holdcroft, Barbara. (2006). What is religiosity?. Catholic Education: A Journal of Inquiry and Practice, Vol. 10

Holt, M.K ., Dorothy, L. E. (2007). Perceived social support among bullies, victims, and bully-victims. Journal Youth Adolescence. DOI 10.1007/s10964- 006-9153-3

Huber, S \& Huber, W. (2012). The centrality of religiosity scale (CRS): Journal of Religion. doi:10.3390/rel3030710

Jacobs, N., Goossens, L., Dehue, F \& Lechner, L. (2015). Dutch cyberbullying victims' experiences, perceptions, attitudes and motivations related to (coping with) cyberbullying: focus group interviews. Faculty of Psychology and Educational Sciences, Open University The Netherlands, Valkenburgerweg

Kowalski, R., Giumetti, G., Schroeder, A \& Lattanner,M. (2014). Bullying in the digital age: a critical review and meta-analysis of cyberbullying research among youth. Psychological Bulletin. DOI: 10.1037/a0035618

Laguna, M., Vecchione, M \& Einsenberg, N. (2015). On the factor stucture of the rosenberg (1965) general self-esteem scale. APA Journals: Psychological Assessment. Vol. 27, No. 2, 621-635

Leach, Berman \& Eubanks. (2008). Religious activities, religious orientation, and aggressive behavior. Journal for the Scientific Study of Religion

Li, Qing. (2007). Bullying in the new playground: research into cyberbullying and cyber victimisation. Australasian Journal of Educational Technology

Li, K. (2010). A study of relationship between cyberbullying and personality of the elders at Kaoshiung. Taiwan. 
Menesini, E., Nocentini, A., \& Palladino, B.E. (2012). Online and offline peer led models againts bullying and cyberbullying. Journal of Psychotema. 24(4), 634-636. ISSN 0214-9915. www.psichothema.com

Mishna, F., Saini, M \& Solomon, S. (2009). Ongoing and online: children and youth's perceptions of cyberbullying. Children and Youth Services Review. 31 1222-1228

Muslimah, A. I., \& Wahdah, N. (2013). Hubungan antara attachment dan self esteem dengan need for achievement pada siswa madrasah aliyah negeri 8 cakung jakarta timur. Volume 6 , No. 1

Notar, C.E , Sharon P \& Jessica R. (2013). Cyberbullying: a review of the literature. Universal Journal of Educational Research. DOI: 10.13189/ujer.2013.010101

Offen, Ilanit. (2012). Social support for adolescents involved in traditional and cyber bullying. California State University, Sacramento

Papalia, D.E., Olds, S.W., \& Feldman, R.D. (2008). Human development (psikologi perkembangan). Jakarta: Kencana Prenada Media Group.

Patchin, J.W., \& Hinduja, S. (2010). Cyberbullying and self-esteem. Journal of School Health. Vol. 80, No. 12

Patchin, J.W., \& Hinduja, S. (2012). Cyberbullying prevention and response : expert perspectives. New York: Routledge

Pratiwi, D. (2011). Pengaruh trait kepribadian, strain, dan interaksi orangtua terhadap cyberbullying pada remaja. Skripsi. Jakarta: Universitas Islam Negeri Syarif Hidayatullah

Rahayu, Flourensia. (2012). Cyberbullying sebagai dampak negatif penggunaan teknologi informasi. Journal of Information System. Universitas Atma Jaya Yogyakarta

Rosenberg, Morris (1965). Society and the adolescent self image. Princeton, NJ: Princeton. University Press

Santrock, John W. (2012). Life-span development.13th Edition. University of Texas, Dallas: Mc Graw-Hill

Sarafino, E.P \& Timothy, W.S. (2011). Health psychology. USA : John Willey \& Sons, Inc

Sarwono, Sarlito. (2010). Psikologi remaja. Jakarta: PT RajaGrafindo Persada

Sheeran, Paschal. (2002). Intention behavior relations: a conceptual and empirical review. European Review of Social Psychology

Seeds, Pamela M., Harkness, Kate L \& Quilty, Lena C. (2010). Parental maltreatment, bullying, and adolescent depression: evidence for the mediating role of perceived social support. Journal of Clinical Child \& Adolescent Psychology, 39(5), 681-692, 2010

Smith, P.K., Mahdavi, J., Carvalho, M., Fisher, S., Russell, S., \& Tippett, N. (2008). Cyberbullying: its nature and impact in secondary school pupils. Journal of Child Psychology and Psychiatry

Spears, B., Philip. S., Owens, L \& Bruce, J. (2009). Behind the scenes and screens insights into the human dimension of covert and cyberbullying. Journal of Psychology. Vol. 217(4):189-196 DOI: 10.1027/0044u3409.217.4.189 
Sulllivan, K., Mark, C \& Ginny,S. (2004). Bullying in secondary schools : what it looks like and how to manage it. London: SAGE A Publication Company

Suralaga, Fadhilah. (2014). Regulasi diri moral sebagai mediator pengaruh goal orientation, orientasi religius, emosi moral dan iklim akademik terhadap integritas akademik. Disertasi :Program Doktor Psikologi Universitas Persada Indonesia Y.A.I

Tamtomo, Aryo. (2014). Hubungan antara stres sekolah dan dukungan teman sebaya terhadap perilaku bullying pada siswa. Tesis; Progam Pacasarjana Universitas Muhamadiyah Surakarta

Taylor, Shelley. (2006). Health psychology. New York: Mc Graw Hill

Waitley, Denis. (1997). Psychology of success: developing your self esteem. New York : McGraw-Hill

Willard, Nancy. (2007). Educator's guide to cyberbullying and cyberthreats. Cyberbullying and Cyberthreats: Responding to the Challenge of Online Social Aggression, Threats, and Distress (Research Press)

http://repository.unhas.ac.id:4001/digilib/fil es/disk1/336/--haryati-16762-

16_cyberb-g.pdf

http://www.unicef.org/indonesia/id/media 2 2169.html

https://kominfo.go.id

http://www.yorku.ca/rokada/psyctest/rosenb rg.pdf

http://news.liputan6.com http://wartakota.tribunnews.com 